\title{
JOGANDO E APRENDENDO COMUNICAÇÃO \\ ENFERMEIRA-PACIENTE
}

Maguida Costa Stefanelli*

STEFANELLI, M.C. Jogando e aprendendo comunicação enfermeira-pacientes. Rev. Esc. Enf. USP, v. 26, n. 2, p. 219-34, Ago. 1992.

Apresenta-se um jogo educativo sobre comunicação enfermeira-paciente. O jogo foi testado por mestrandas e utilizado por alunas do curso de graduação. Foi avaliado pelos alunos, juizes $c$ autoras que o consideraram eficiente e adequado para $o$ ensino do assunto e'm questäo.

UNITERMOS: Comanicaşäo. Jogo Educativo. Relações enfermeira-paciente.

Ao considerarmos a comunicação como uma necessidade humana básica e um processo que sustenta toda a assistência de enfermagem e o desenvolvimento do relacionamento terapêutico enfermeira-paciente, torna-se imperioso que o ensino sobre comunicação e comunicação terapêutica seja ministrado nas escolas de enfermagem em nível de graduação. Acreditamos que este assunto deva também fazer parte de programas de educação continuada e de programas de pós-graduação com o objetivo de desenvolvimento de pesquisas e novas estratégias de ensino.

STEFANELLI (1985) realizou estudo no qual mostra que o uso da comunicação terapêutica pode ser aprendido. Após ministrar aulas sobre comunicação enfermeira-paciente, leva os alunos a debaterem um instrumento, por ela elaborado, contendo exemplos de trechos ou partes da interação, que ocorre entre enfermeira e o paciente. Tais exemplos são discutidos quanto à sua propriedade, adequação e possíveis alternativas de que a enfermeira poderia valer-se nas situações apresentadas. Durante o debate a Autora introduz informações adicionais sobre o ambiente onde se havia dado a interação e a comunicação não verbal de um dos participantes ou de ambos. As alunas discutem todos os exemplos demonstrando interesse, introduzindo modificações no ambiente e visualizando alternativas de solução (STEFANELLI, 1985). Isto refletiu na prática, pois era comum ouvir das outras docentes da disciplina "as alunas estão conseguindo identificar as técnicas de co-

* Enfermeira. Professor Titular do Deyartamento de Enfermagem Materno-Infantil e Psiquiátrica da Escola de Enfermagem da Universidade de São Paulo - disciplina Enfermagem Psiquiátrica I. COREN SP 2293 
municação”, “. . veja só, ela usou até a técnica sumarizar, identificando-a como técnica que ajuda a...".

Após algum tempo, começamos a indagar novamente:

Por que será tão difícil para as alunas a utilização e identificação das técnicas de comunicação terapêutica, principalmente quando o ensino destas é ministrado em disciplinas anteriores? Por que não as utilizam no momento certo? - Por que só se utilizam de perguntas, quando seria possível estimular a comunicação do paciente utilizando outras técnicas?

Por que só se reportam às técnicas de comunicação terapêutica e não a outros aspectos da comunicação geral, como por exemplo, comunicação não verbal, confirmação, dupla mensagem, problemas de espaço, toque?

Com base na revisão de literatura sobre o uso do jogo educativo em enfermagem, elaborada por STEFANELLI (1990-1991) e na introdução deste estudo realizamos este trabalho com os seguintes objetivos: 1. elaborar um jogo educativo para ensino e reforço da aprendizagem da comunicação enfermeira-paciente e 2. avaliar o jogo elaborado como estratégia de ensino.

\section{METODOLOGIA}

População e local do estudo

A população do estudo foi constituída de 44 alunas do Curso de Graduação da Escola de Enfermagem da Universidade de São Paulo (EEUSP). Destas, 22 cursavam Fundamentos de Enfermagem Psiquiátrica, no terceiro semestre letivo, e 22 cursavam Enfermagem Psiquiátrica, no sétimo semestre em 1989. Nessas disciplinas há o ensino sistematizado de comunicação em enfermagem, ministrado pela Autora.

\section{Elaboração do instrumento}

Inicialmente, após reflexão sobre a literatura disponível, elaboramos uma lista de mensagens sobre conceitos de comunicação geral e de comunicação enfermeira-paciente, na qual foram incluídos, também, tópicos sobre as técnicas de comunicação terapêutica utilizadas no relacionamento da enfermeira com o paciente. Esta lista foi revista dez vezes (pela Autora) até que chegamos à conclusão de que ela poderia propiciar reflexão e estimular a discussão sobre os referidos tópicos o que exigira a evocação dos conceitos básicos sobre o assunto, não expressos nas mensagens apresentadas. Terminamos assim o primeiro estágio da "cronologia de avaliação" de um jogo, preconizada por THIAGARAJAN (1977), adotado como referencial metodológico para a elaboração do jogo a ser utilizado neste estudo. Este autor denomina o primeiro estágio de auto-avaliação. Submetemos este rol de mensagens à apreciação de quatro juízes considerados peritos no as- 
sunto. A primeira, professora de Enfermagem Psiquiátrica, fez curso de Especialização em Enfermagem Psiquiátrica nos Estados Unidos, e é Doutora em Enfermagem pela USP. O segundo, professor de Fundamentos de Enfermagem, disciplina na qual é ministrada uma unidade sobre Comunicação. A terceira, professora de Fundamentos de Enfermagem, estava elaborando sua dissertação sobre comunicação não verbal na interação enfermeira-paciente, durante a consulta de enfermagem. A quarta, uma ex-paciente, de hospital geral, de nível universitário, formada em Letras, com preparo didático pedagógico, conhecimentos sobre semiologia da comunicação e comunicação geral e terapêutica enfermeira-paciente. Esta leu todas as mensagens e discutiu-es uma a uma, com a Autora, enfatizando a necessidade de toda enfermeira conhecer os aspectos mencionados, a fim de perceber o paciente como ser humano.

Houve uma concordância de $100 \%$ entre os juízes sobre a manutenção de todas as mensagens; podemos dizer o mesmo sobre a validação da compreensão das mesmas, pois apenas um questionou o conteúdo de três delas: 1 . As técnicas de comunicação mais importantes são as do grupo clarificação. 2. As técnicas de comunicação mais importantes são as do grupo de expressão. 3. As técnicas de comunicação mais importantes são as do grupo validação.

Quando explicamos que estas três foram colocadas para estimular a reflexão e discussão sobre os três grupos, o juiz concordou que para atingir estes objetivos os conceitos deveriam ser mantidos.

Acreditamos assim ter cumprido o segundo e o terceiro estágios da "cronologia de avaliação" de THIAGARAJAN (1977), isto é, a avaliação por peritos sobre o conteúdo do instrumento e do juizo sobre a viabilidade do jogo, que tiveram $100 \%$ de concordância em ambos os casos.

A verificação de viabilidade do jogo, que seria a tentativa de jogar informalmente, foi cumprida quando a Autora e dois dos juízes analisaram e discutiram o conteúdo de cada mensagem, o que é praticamente uma tentativa de jogar. A autora já havia simulado o jogo, sozinha, várias vezes, tentando desempenhar o papel dos participantes. Não foi verificada a necessidade de alterações.

Após estas primeiras etapas consideramos o jogo como pronto para ser testado. Foi feito um jogo com 35 cartas, contendo cada carta uma mensagem diferente, previamente avaliada. Tivemos o cuidado de não elaborar um jogo com número excessivo de cartas para não cansar os jogadores e provocar desinteresse, como foi constatad por THIAGARAJAN (1977).

As cartas do jogo foram confeccionadas por um colega e plastificadas. As regras do jogo foram elaboradas pela autora deste estudo.

Pré-teste

Prontos o jogo de cartas e as regras do jogo, podíamos iniciar o quarto-estágio, recomendado por THIAGARAJAN (1977), ou seja, tes- 
tá-lo antes de utilizá-lo como estratégia de ensino. O pré-teste foi realizado com três alunas de mestrado, da área de Enfermagem Psiquiátrica. Estas podiam ser consideradas como peritas no assunto, uma vez que já eram profissionais da referida área, na qual a habilidade em comunicação é mais exigida; duas eram professoras de Enfermagem Psiquiátrica e a terceira, enfermeira da área assistencial. No semestre anterior haviam estudado, discutido e apresentado, sob a forma de seminário, a fundamentação e o referencial teórico sobre o processo de comunicação, bem como a comunicação terapêutica, as técnicas desta e sua utilização no relacionamento enfermeira-paciente.

Após testarem o uso do jogo de cartas, as mestrandas o avaliaram quanto a sua adequação para o ensino de comunicação e a pertinência de sua utilização no ensino de graduação em enfermagem. Consideraram, unanimemente, que o jogo: "facilita tornar o ensino dinâmico"; "reforça o aprendizado"; e "serve para avaliar as aulas dadas sobre o assunto".

\section{Procedimentos}

O jogo foi realizado com as alunas das disciplinas Fundamentos de Enfermagem e Enfermagem Psiquiátrica, referidas no item "População e local".

No programa de cada disciplina há uma unidade sobre relacionamento enfermeira-paciente que é ministrada pela Autora. Esta unidade inclui 9 horas de aulas sobre os conceitos básicos de comunicação terapêutica e suas técnicas, esclarecimentos de dúvidas e discussões sobre o assunto.

No início da unidade, cada turma foi avisada de que, ao término desta, a professora iria utilizar outra estratégia de ensino sobre o assunto. Não foi dada informação se esta estratégia seria o jogo.

$\mathrm{Na}$ hora da aplicação desta estratégia, o jogo foi-lhes apresentado como um recurso para facilitar o aprendizado dos principais conceitos teóricos emitidos, para estimular reflexão, discussão e fixação de conceitos sobre o assunto, de modo participativo, em grupo. Antes do início do jogo, foi feita a descrição do jogo de cartas e das regras de seu uso (ANEXO). Houve esclarecimentos de que o objetivo não continha a idéia de competição e que todos seriam ganhadores, pois o importante seria a aprendizagem em grupo.

A seguir, foi solicitado às alunas que formassem grupos em número de quatro a sete, de modo que na distribuição das cartas um número destas, igual ao número de participantes permanecesse sobre a mesa. Foi dada plena liberdade para a formação dos grupos, uma vez que tínhamos limitação de tempo para o jogo em si e, por que não pareceu significativa, para o jogo, a indicação de grupos previamente determinados; além disso, a inibição que ocorre normal- 
mente quando se formam grupos de discussão, poderia ser mais rapidamente superada se as alunas se sentissem mais confortáveis no grupo.

Foi-lhes assegurada plena liberdade de participação, tendo sido as mesmas avisadas de que não seriam avaliadas pela atuação durante 0 jogo.

A idéia de não serem discutidos todas as mensagens das cartas foi para despertar na salunas a curiosidade e o consequiente interesse pelas mensagens restantes. As cartas que restavam funcionavam como cartas substitutas para as mensagens que as participantes julgavam "fracas", não tão relevantes quanto a outras ou ainda, caso encontrassem dificuldade para argumentar sobre algumas das mensagens recebidas, na distribuição das cartas.

Foram formados quatro grupos de alunas de Fundamentos de Enfermagem e quatro de Enfermagem Psiquiátrica, em momentos distintos utilizando ao todo quatro salas.

Após a realização do jogo solicitamos aos grupos que fizessem a avaliação do mesmo como estratégia de ensino tendo em mente seus objetivos. Cumprimos assim o quinto estágio, ou seja, testar no campo (THIAGARAJAN, 1977).

Ao término de cada disciplina, estas alunas avaliaram de novo, o jogo, desta vez individualmente, o que se assemelha ao sexto estágio de THIAGARAJAN (1977), chamado avaliação mediata.

Como preconizado por THIAGARAJAN (1977), a utilização do jogo pela Autora, com os alunos de Fundamentos de Enfermagem, foi feita com a presença de dois juízes; estes já haviam avaliado os conceitos arrolados para a confecção do jogo; a sua presença foi solicitada para evitar parcialidade no julgamento da Autora e verificar possíveis discrepâncias entre a percepção desta e a dos peritos, professores de Fundamentos de Enfermagem.

Estes peritos fizeram uma avaliação imediatamente após o jogo e outra ao término da disciplina Fundamentos de Enfermagem, ocasião em que já haviam tido oportunidade de observar os alunos em interação com pacientes, durante o ensino teórico-prático.

A utilização do jogo com as alunas de Enfermagem Psiquiátrica, foi feita apenas com a Autora presente, que é professora desta disciplina há 22 anos.

\section{ANALISE E COMENTARIOS}

A população do estudo, a Autora e peritos fizeram avaliação imediata e mediata da utilização do jogo elaborado. 
Como não houve discrepância, entre as duas turmas, nas observações e notas de campo realizadas pela Autora, as mesmas serão analisadas em conjunto.

Após esclarecer as duas turmas de alunas, população do estudo, sobre as regras do jogo, as alunas de cada semestre formaram quatro grupos.

Desde o início do jogo percebemos nítido interesse das alunas e o seu envolvimento nas discussões das mensagens contidas nas cartas do jogo.

Foi assegurada a discussão sobre, no mínimo, 28 mensagens, em cada grupo.

Às vezes, uma aluna era interrompida por outra, em sua exposição, mas logo outro elemento do grupo lembrava as regras do jogo, com frases como: "Vamos ouví-la até o fim", "Como assim? Termine seu pensamento". Houve interferência da Autora ou dos juizes somente para lembrar às participantes o direito, de cada uma, de argumentar sobre o conceito por ela escolhido, de ser ouvida e para esclarecer dúvida.

Quando necessário foi dado esclarecimento sobre a mensagem em discussão, que só aconteceu duas vezes, quando surgiu a mesma dúvida para dois grupos, de cada turma, sobre a mensagem referente à "negação ou rejeição". Perguntaram: "O que é mesmo negação? É rejeição?".

Esta discussão sugere que devemos suprimir o termo "rejeição" e conservar apenas "negação" na carta do jogo. O termo rejeição pode dar margem a dupla interpretação devido a sua utilização, com sentido diferente na prestação da assistência de enfermagem.

Após cada aluna ler o conceito escolhido e argumentar sobre sua importância na comunicação enfermeira-paciente, seguia-se uma discussão acalorada entre elas para a tomada de decisão sobre que mensagem deveria prevalecer em cada rodada, qual a mais significativa.

Apesar do envolvimento verificado na discussão, o respeito mútuo foi mantido durante todo o tempo e a expressão do pensamentto fluiu livremente.

Acreditamos que esta liberdade entre as participantes ocorreu, em parte, em consequiência do modo como foram formados os grupos e da explicação de que não haveria ganhadores ou perdedores. O importante seria a discussão entre elas; o resultado da reflexão sobre as mensagens contidas em cada carta e a articulação com outros conceitos sobre o assunto.

Foi interessante e prazeroso observar que estas articulações ocorreram, com mais frequiência, no momento das discussões em grupo, 
quando as alunas tentavam usar o conhecimento teórico sobre comunicação, adquirido no decorrer da unidade, para argumentar sobre a mensagem escolhida e, o que é mais importante, para estimular as colegas a se expressarem ou a recordarem do significado da mensagem.

Esta estimulação foi necessária poucas vezes porque, de modo geral, todas as estudantes se envolveram no jogo, num clima aparentemente sem ansiedade, pois riam e falavam livremente, num processo de ajuda mútua.

Às vezes, a escolha da mensagem mais significativa tornava-se difícil para os grupos, porque seus participantes achavam que todas as mensagens eram importantes e nenhuma delas poderia ser descartada. Acreditamos que este foi um dos momentos mais ricos desta estratégia de ensino. As alunas reiniciavam a discussão, demonstrando grande atenção e evocando outros conceitos emitidos durante as aulas que precederam a discussão, a fim de fundamentar sua argumentação; valeram-se também de suas experiências de vida anterior.

A utilização da própria experiência, na discussão, e sua associação com novos conhecimentos é muito importante para estimular o sentimento da pessoa de que é aceita e reforçar sua identidade em termos da experiência vivida.

A seguir, refletiam juntas sobre os argumentos que conseguiram trazer para o grupo, até chegarem ao consenso sobre a escolha da mensagem.

Estes aspectos mostram que com a utilização do jogo de cartas, foi atingido o objetivo de estimular a reflexão sobre o processo de comunicação enfermeira-paciente, dentro de um ambiente de cooperação e participação. Compartilhar idéias permitiu a estimulação das áreas de atenção, raciocínio, memória, pensamento, bem como expressão verbal deste, o que consequientemente, pode ter influído no aprendizado dos conceitos sobre comunicação.

Podemos afirmar que o jogo constituiu uma excitante experiência de troca de idéias e informações entre as participantes, que tiveram a oportunidade de compartilhar a responsabilidade da própria aprendizagem, fazer avaliação com pares e desenvolver o processo de tomada de decisão.

Os resultados descritos até aqui permitem-nos afirmar que o jogo, como foi organizado, estimulou, também o desenvolvimento dos domínios afetivo e cognitivo. O respeito mútuo e a aceitação cio outro demonstrados pelas alunas e a forma que encontraram para solucionar os impasses surgidos são prova desta afirmação. Por exemplo, o empate na escolha do conceito mais significativo ocorreu em dois grupos de alunas, uma de Fundamentos e outra de Enfermagem Psiquiátrica; em ambos os casos os participantes resolveram deixar a decisão da escolha da carta mais significativa para o final do jogo; 
continuaram a discussão livremente e no final retomaram o "caso do empate" e nos dois grupos foi dito claramente: "agora vamos avaliar e decidir porque os dois conceitos são igualmente importantes para nós, deixamos os dois ou escolhemos um deles". Após nova discussão cada grupo decidiu por um dos conceitos $€$ uma das alunas, de um dos grupos, comentou com a colega que relutava em acatar a decisão final: "Toda decisão implica em um ganho e uma perda. Temos de aprender a trabalhar com os dois lados", isto foi dito em tom de voz convincente, sem hostilidade aparente; a aluna concordou e disse que reconhecia que precisava aprender como aceitar "essa decisão". Este é um dos pontos positivos do uso do jogo como estratégia de ensino. Podemos dizer que há "aprendizagem afetiva", como por exemplo, o estímulo para mudança de atitude, oportunidade de amadurecimento e a demonstração de sentimento empático. Estes elementos podem ser observados no comentário anterior.

Após o jogo observamos algumas alunas comentando: "Até que enfim conseguimos pensar, sentir e agir sem brigas para aprender logo".

O jogo é um processo interativo que implica na aquisição de conhecimento e habilidade cognitiva, afetiva e psicomotora, quando esta é incluída.

O envolvimento de todas as alunas no jogo foi visível. Em dado momento estas retiravam os agasalhos, como se estivessem com calor, ou mudavam de posição, como se procurassem outra mais cômoda para melhor argumentar ou contra-argumentar.

Avaliação imediata dos juizes

Os dois peritos que acompanharam a utilização do jogo na disciplina Fundamentos de Enfermagem fizeram uma avaliação imediata e outra mediata.

$\mathrm{Na}$ avaliação imediata de um deles encontramos:

1. "Considero o jogo bastante válido como reforço pelas discussões havidas, nos quatro grupos, sobre os conceitos de comunicação dados anteriormente"; "porque possibilitou ao aluno desenvolver sua própria habilidade de comunicar-se, transmitindo suas idéias e suas crenças para o grupo"; e "porque estimula o uso da argumentação mais corretamente bem como o inter-relacionamento entre os conceitos" e "o criar argumentação foi válido".

2. "Os grupos pareceram bastante estimulados, pelo tom dos discursos ouvidos, ênfase nas argumentações, gestualidades dos membros para dar ênfase à complementação das idéias. Ninguém se mostrou indiferente à sua carta do jogo".

3. "Outro dado válido foi a dificuldade demonstrada pelos grupos para excluir mensagens e a utilização de todo o tempo dado para o jogo". 


\section{O outro perito fez os seguintes comentários:}

1. "Acompanhando os participantes durante o desenvolvimento do jogo educativo, pude observar que este recurso estimula a argumentação, que por sua vez pressupõe conhecimento do assunto e raciocínio".

2. "Esta estratégia possibilita e até obriga a participação de todos os componentes, de tal forma que mesmo os mais inibidos têm a oportunidade de emitir opinião sobre o assunto".

3. "A validade desta estratégia é indiscutível por ser um recurso que consolida e reforça conceitos aprendidos".

Podemos verificar que a percepção dos peritos é, em sua grande maioria, coincidente com a percepção da Autora, o que é tranquuilizador, pois THIAGARAJAN (1977) recomenda a presença destes na utilização do jogo para evitar a subjetividade na avaliação do mesmo e, a Autora o utilizou sozinha na turma de Enfermagem Psiquiátrica.

\section{Avaliação imediata das alunas}

A estas foi solicitada imediatamente após o término do jogo a avaliação em grupo, por escrito, da experiência vivenciada. K interessante notar que, nessa fase, as alunas de Fundamentos de Enfermagem e de Enfermagem Psiquiátrica não divergiram entre si; ressaltaram a parte técnica, a importância e validade do jogo para a fixação, revisão e avaliação do aprendizado.

Algumas frases podem elucidar esta observação: "leva à reflexão com respeito mútuo"; "é uma experiência construtiva e muito boa para ajudar a fixar e relembrar conceitos"; "oportunidade para todos participarem ativamente"; "válido para aprofundamento no assunto e integração intra e interpessoal".

Vale notar, igualmente, a percepção das alunas de que, na discussão dos conceitos sobre comunicação, tiveram, também de aplicá-lo, avaliá-lo e de se avaliarem mutuamente, para, dentro de um clima de respeito mútuo, chegarem à tomada de decisão. Exemplos: "o debate é importante para o desenvolvimento do respeito mútuo"; "a metodologia atingiu plenamente os objetivos propostos: reflexão, avaliação e reforço dos conceitos apresentados em sala de aula"; "bom porque permite aplicação dos próprios conceitos de comunicação na discussão".

Ao lado destes comentários, as alunas de Fundamentos de Enfermagem fizeram crítica à presença de três pessoas, a Autora e os juízes; acharam que a circulação destes, pelos grupos dispersa a atenção das alunas e que uma pessoa seria suficiente. Em Enfermagem Psiquiátrica o jogo foi realizado somente com a Autora, sem problemas. 
THIAGARAJAN (1977) preconiza a presença de juízes ou peritos durante o jogo. Para tal teremos de estudar um meio de utilizá-los sem que constituam um estímulo negativo.

Na nossa opinião a utilização ou não de juízes poderá ficar a critério do pesquisador, porém, este terá de desenvolver habilidade para observar e anotar o que se passa durante o jogo, a fim de limitar a subjetividade na avaliação e o efeito de sua interferência.

Houve divergência entre juízes e alunas, quanto à opinião da presença de três pessoas para auxiliarem no esclarecimento de dúvidas; as alunas haviam alegado que mais de uma pessoa dispersa a atenção e os juízes haviam percebido a sua presença como necessária para esclarecer dúvidas. A Autora acredita que para 4 grupos de até 7 alunas, uma pessoa adequadamente preparada é suficiente desde que os grupos fiquem em salas próximas.

\section{Avaliação mediata da Autora}

A avaliação mediata da Autora é tão entusiástica quanto a dos peritos apesar de, com a turma de Fundamentos de Enfermagem, só ter tido interações ocasionais. O entusiasmo aumentou quando, ao término da disciplina Enfermagem Psiquiátrica, pôde perceber nas alunas o seu conhecimento sobre comunicação, o seu envolvimento no uso da mesma e o interesse em conhecer os resultados deste trabalho o que demonstra ter sido atingido um dos objetivos do ensino desta matéria que é adquirir habilidade no uso da comunicação com o paciente.

\section{Avaliação mediata dos juizes}

Os juízes mencionaram a importância e utilidade do jogo como elemento reforçador de idéias e conceitos ministrados nas aulas teó ricas. Consideram, também, a importância dos diálogos e discussões ocorridos durante o jogo, como elementos para que a aluna pudesse vivenciar o processo de comunicação - a arte de falar, defender seus pontos de vista face a face, relacionar idéias, avaliar argumentações e tomada de decisões. A presença da parte afetiva durante o jogo pôde ser evidencida, nesta avaliação, pelos comentários: “. . . a euforia e veemência das discussões" e "...fixação de conceitos por meio do raciocínio e argumentação...". Isto pôde ser percebido pela veemência com que alguns elementos defenderam seus pontos de vista...".

Um dos peritos comentou o resultado obtido em uma pergunta, da prova escrita para avaliação do aluno, sobre comunicação ao término da disciplina. Ele afirma que pelas respostas houve "boa compreensão dos conceitos abordados"; acrescentou, ainda, que esta estratégia de ensino não só é útil para a aluna como também para avaliar o professor, sua capacidade expositiva e sua correta formulação de conceitos; outro acrescentou que o jogo serve para avaliar não só 
o grau de assimilação dos alunos bem como a estratégia de ensino, que poderá ser corrigida e modificada, se necessário. Ambos, mencionaram que o jogo educativo é válido para várias disciplinas e diferentes tipos de temas.

Um deles, comentou, a importância da presença de alguém com domínio do assunto (peritos) para esclarecer conceitos, tirar dúvidas e ressaltar exemplos que facilitem a compreensão do próprio "comportamento comunicativo" dos elementos do grupo.

Verificamos, que pelas avaliações mediatas os dois juízes reforçaram o que haviam referido na imediata só que com maior segurança, pois fizeram afirmações de quem observou de perto a comunicação das alunas com os pacientes.

\section{Avaliação mediata das alunas}

Esta foi feita ao término das disciplinas Fundamentos de Enfermagem e Enfermagem Psiquiátrica. Em geral, as avaliações individuais corroboraram as avaliações feitas em grupo, anteriormente.

$\mathrm{E}$ interessante observarmos os pontos coincidentes e os divergentes, ou melhor, os pontos não coincidentes, pois não chegam a ser realmente divergentes, mas resultado de percepções diferentes. Causou certa estranheza que somente a turma de Fundamentos de Enfermagem, que é do terceiro semestre letivo, considerasse o jogo como prática para a vida real. Podemos inferir que, se as alunas foram capazes de utilizar a teoria na discussão com os pares, elas, experimentarão menos ansiedade na interação com os pacientes, no caso, na situação real. Quando a aluna percebe a relevância do assunto estudado para aplicação na prática, a motivação para o aprendizado aumenta.

$\mathrm{Na}$ avaliação escrita das alunas do sétimo semestre, não encontramos referência a este aspecto. Verbalmente, porém, comentaram com a Autora sobre a importância do uso de novas estratégias de ensino, principalmente quando elas permitem "vivenciar os conceitos aprendidos e, em grupo"; falaram, ainda, sobre a importância do jogo em si como um instrumento que facilita a concentração de atenção, estimula o raciocínio e a capacidade de argumentação, o que permite maior conhecimento e entrosamento das colegas.

Quanto a este último aspecto podemos salientar que ela já é um preparo para a vida real, porque as alunas vão encontrar pacientes com personalidades diferentes, de várias culturas, com as quais elas têm de aprender a interagir.

$\hat{E}$ interessante perceber que a palavra reforço foi citada várias vezes e até grifada. Isto sugere que o uso do jogo deva ser associado a outras estratégias de ensino. 
A presença de "teorias" nas mensagens selecionadas pelas alunas pode indicar a preocupação dos professores em introduzir o ensino destas desde o início do curso, e a aceitação de uma linha norteadora da assistência de enfermagem.

Quando a aluna seleciona a "comunicação como um processo recíproco" e dá destaque à importância do contexto, pođemos inferir que ela considera a si própria e ao paciente como elementos participantes que interagem dentro de um contexto e sofrem influência deste e da interação havida.

interessante registrar ainda que a coincidência das mensagens selecionadas não ocorreu em todos os grupos de alunas, de ambas as turmas; este fato pode ser plenamente justificado por expressões, das alunas das duas disciplinas. Por exemplo: "Tudo é tão importante, como selecioná-las?" e "Um depende do outro, se seleciono esse conceito, estarei descartando outro que também deve ser considerado".

Analisando as mensagens não coincidentes selecionadas, podemos perceber que as alunas de Fundamentos de Enfermagem, apesar de selecionarem pressupostos básicos, escolheram mais as mensagens que partiam do específico para o geral. Por outro lado, as áe Enfermagem Psiquiátrica selecionaram os conceitos gerais mais abrangentes e as duas técnicas de comunicação - "ouvir reflexivamente" e "usar terapeuticamente o silêncio" - consideradas básicas para o desenvolvimento da relação enfermeira-paciente e para a utilização das outras técnicas de comunicação terapêutica. Referiram-se, ainda, aos modos não terapêuticos.

Estes fatos não deixam de indicar uma evolução das nossas alunas, ao longo do curso e a consequiente preocupação com o todo, sem prejuízo da especificidade.

Podemos concluir que o uso do jogo foi considerado válido, eficiente e adequado para o ensino da comunicação enfermeira-paciente, pelas alunas, juízes e Autora.

\section{CONCLUSÓES E COMENTARIOS FINAIS}

Podemos afirmar que houve interesse e desenvolvimento nas áreas cognitiva, afetiva e pragmática.

Cognitiva porque as alunas souberam utilizar a teoria que lhes foi oferecida para discutir sobre as mensagens contidas nas cartas de jogo, argumentado e contra-argumentado com propriedade. Para tal valeram-se também de seu repertório, solicitando esclarecimentos quando necessário.

Afetiva porque o envolvimento das alunas foi perceptível, tanto pela participação verbal como pela não verbal, esta demonstrada por tom de voz, gestualidade e postura na cadeira; o clima foi de aceitação 
e respeito mútuos, procurando umas levar as outras a entenderem seu comportamento.

Pragmática porque o jogo propiciou a prática efetiva da teoria sobre comunicação, que lhes havia sido ensinada, nas suas interações o que demonstra a importância da comunicação em outras situações de vida.

O uso do termo pragmática pode intrigar o leitor, mas é o melhor para ser usado neste momento, porque não se trata de domínio psicomotor e sim da associação das áreas cognitiva e afetiva e de sua utilização na prática, o que foi percebido claramente por alunas, juízes e Autora.

As alunas também extrapolaram sua percepção para situações comuns de vida e para outras áreas de enfermagem; valeram-se, para isto, também de suas experiências anteriores nos diálogos e discussões, como percebido pelos peritos e comentados pelas alunas. Estas chegaram a afirmar que o jogo permitiu o aprofundamento do conhecimento e a integração intra e interpessoais, tendo, portanto, dado oportunidade para vivenciar o processo de comunicação em uma situação menos estressante; isto, talvez porque fora abolido o caráter de avaliação, pelo professor, da participação das alunas no jogo.

Pelos comentários e avaliação feitas por juízes e alunas, podemos afirmar que o jogo educativo atende às características da avaliação formativa, permitindo à aluna fazer correções no seu padrão de desempenho durante o transcorrer do ensino de toda uma disciplina ou de apenas uma de suas unidades.

Os termos "reforço de conhecimento" e "consolida o assunto" pressupõem conhecimento anterior e deixam evidente a necessidade dos alunos terem informações prévia para se sentirem mais confiantes durante o jogo.

A integração deste jogo com leitura, exposição, aula, entre outros, torna-se necessária, porque as pessoas têm estilos diferentes de aprendizagem. Não se pode propor um jogo para um grupo de alunas que experimenta por este a mesma aversão que tem pelo uso inadequado do retroprojetor. O professor tem de utilizar sua criatividade para atender às diferenças individuais, sem perder a noção da realidade, porque as turmas de alunas em sala de aula, às vezes, são numerosas.

A Autora não vê o jogo como substituto da preleção ou outros métodos mais tradicionais de ensino, e sim como coadjuvante destes e como reforço. A leitura de bibliografia específica pode ser indicada a fim de servir de subsídio sobre o assunto contido no jogo e para as alunas partilharem o conhecimento com seus pares mais efetivamente.

Chamamos a atenção para o fato de que o jogo é apenas uma estratégia a mais e não panacéia para todas as falhas do ensino. Desde que usado com propriedade e de forma adequada aos diferentes níveis de ensino pode, na opinião e na experiência vivida pela Autora, ser usado em cursos de graduação, extracurricular e de pós-graduação. 
STEFANELLI, M.C. Gaming and learning nurse-patient communication. Rev. Esc. Enf. USP, v. 26, n. 2, p. 219-34, Aug. 1992.

The autor present an educative game to teach nurse-patient communication. The game was tested by graduate students and utilized by the undergraduate students. Those students, judges and the Author considered this game efficient and adequate to the teaching of the topic under study.

UNITERMS: Communication. Game educativc. Nurse-patient relationship.

\section{REFERENCIAS BIBLIOGRAFICAS}

STEFANELLI, M.C. Ensino de técnicas de comunicação terapêutica enfermeira-paciente. São Paulo, 1985. 163 p. Tese (Doutorado) - Escola de Enfermagem, Universidade de Săo Paulo.

Comunicação enfermeira-paciente: teoria, ensino e pesquisa. São Paulo, 1990. 139 p.

Tese (Livre Docéncia) - Escola de Enfermagem, Universidade de São Paulo.

O uso do jogo educativo no ensino de enfermagem. Rev. Esc. Enf. USP, v. 25, n.

3 , p. 347-61, 1991.

THIAGARAJAN, S. Evaluation of simulations and games: a comprehensive procedure and a case history. Health Educ. Monograf., v. 5, p. 64-75, 1977. Suplement. 1.

\section{A NEXO}

\section{O JOGO “COMUNICAÇAO ENFERMEIRA-PACIENTE" E SUAS REGRAS *}

\section{Destinatários}

Alunas de enfermagem estudando os processos de comunicação e comuni. cação terapêutica no relacionamento com o paciente.

\section{Objetivo}

Estimular a reflexão e discussão, em grupo, das mensagens emitidas nas cartas do jogo sobre os processos de comunicação e comunicação terapêutica no relacionamento enfermeira-paciente.

\section{Material}

Um jogo de 35 cartas contendo mensagens sobre o processo de comunicação e de comunicação terapêutica no relacionamento enfermeira-paciente.

Duração: uma hora

\section{Número de participantes}

4 a 7 alunas por grupo, sendo uma delas escolhida como coordenadora do grupo. Se as participantes não se conhecerem, iniciar pela apresentação das mesmas.

\section{Espaço necessário}

Salas onde cada grupo possa jogar sem sofrer interferência de ruidos dos outros grupos.

* Estas regras, modificadas e ampliadas pela Autora, foram, em parte baseadas nas contidas no jogo «El nafpe de la educación continuada para el auto-culdado», de CAMPOS \& LANGE, apresentado no «Seminário de Educação para a Autocuidado em Saúde», na EEUSP, em 1987. 


\section{Regras do jogo}

1. De acordo com o número de jogadores, as cartas são distribuídas equitativamente, ao acaso, e de modo a assegurar que no mínimo 28 cartas sejam analisadas pelo grupo. As outras sete cartas deveráo permanecer na mesa. E permitido a cada jogador trocar, pelo menos uma das cartas recebidas, por uma das que ficaram sobre a mesa.

2. Na primeira rodada do jogo, cada aluna escolhe uma mensagem.

3. Após cada aluna escolher a mensagem, ela a lê para o grupo, expõe - que pensa sobre a mesma, fundamenta sua explicação, informa sobre sua importância e dá os esclarecimentos que julgar necessários.

A rodada termina quando todas do grupo expuseram suas idéias a respeito de cada carta escolhida.

4. A seguir há a discussão em grupo para a escolha da mensagem ou afirmação, considerada, pelo grupo, como a mais significativa para a comunicação enfermeira-paciente. A carta escolhida fica no centro da mesa e as outras são descartadas.

5. A operação é repetida, a partir do item 2 , até que se esgotem 28 mensagens, no minimo.

6. Se o grupo esgotar as 28 mensagens antes de completar uma hora, cada participante pode pegar uma das cartas restantes que ficaram sobre a mesa e jogar mais uma rodada.

7. Terminando o jogo, a coordenadora do grupo providenciará para que as mensagens escolhidas sejam registradas em uma folha de papel.

8. Quando o professor acompanha, durante todo o tempo, o jogo dos diversos grupos, ele pode dar o mesmo por encerrado ao término do item 7, uma vez que ao passar pelos grupos, orienta sobre possiveis dificuldades e dúvidas surgidas, do início ao fim do jogo.

9. Se as estudantes optarem por uma reunião de todos os grupos em uma sala de aula, esta pode ser feita. São apresentadas, então, as mensagens prevalentes em cada grupo, tendo elas liberdade para rediscutí-las. Quando o professor julgar necessário essa reunião geral, ele também poderá propốla.
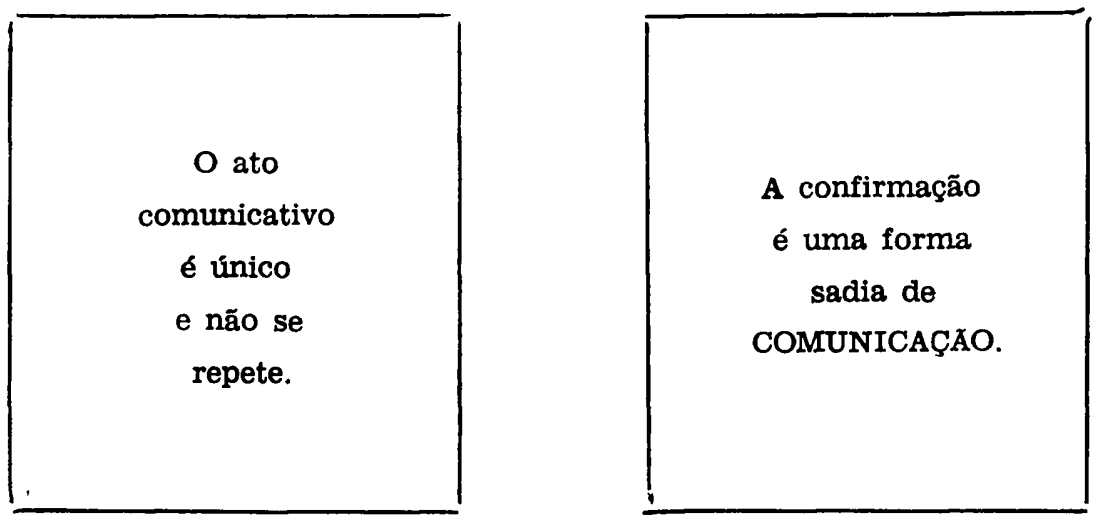

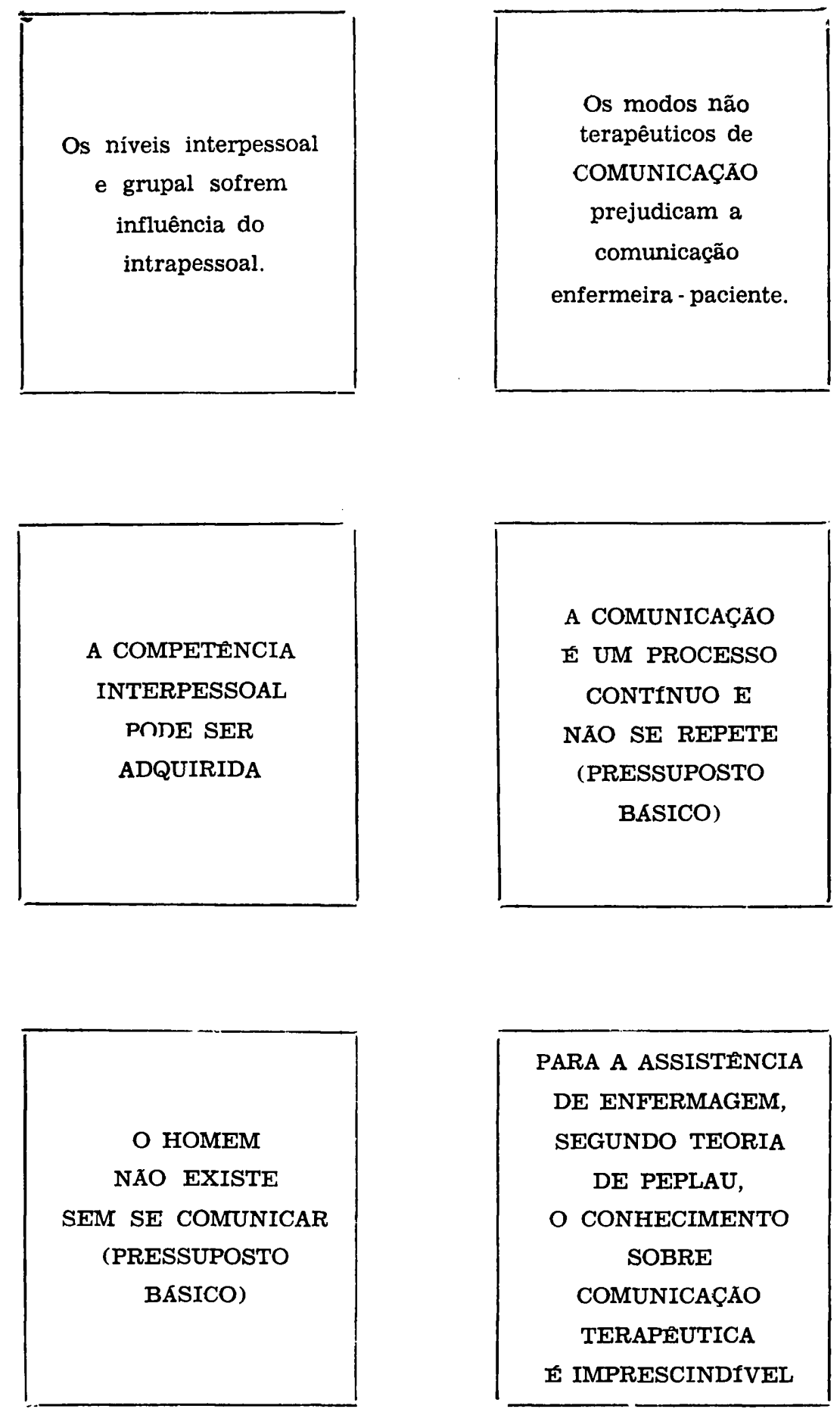

PARA A ASSISTENCIA

DE ENFERMAGEM, SEGUNDO TEORIA DE PEPLAU, O CONHECIMENTO SOBRE COMUNICAÇAO TERAPEUTICA E IMPRESCINDIVEL 